\title{
Quentin Skinner e a liberdade republicana em Maquiavel
}

\author{
Alberto Ribeiro G. de Barros
}

Universidade de São Paulo 

No esforço de reconstrução do paradigma republicano que se encontra nas fundações do pensamento político moderno, Skinner tem atribuído uma atenção especial à ideia de liberdade (Skinner, 1996, pp. 25-209). O seu trabalho historiográfico tem sido justificado pela necessidade de recuperar uma concepção de liberdade capaz de superar a dicotomia propagada pelo liberalismo entre liberdade negativa e liberdade positiva.

Em The Paradoxes of Political Liberty, Skinner examina duas proposições sobre a liberdade, que têm sido avaliadas como paradoxais (Id., 1984, pp. 227-250). A primeira enuncia que só é possível sermos livres numa sociedade política que permita uma efetiva participação na vida pública e, por isso, se desejamos assegurar nossa liberdade, devemos devotar nosso ser tanto quanto possível à atividade política. Ela é considerada paradoxal porque associa liberdade à participação política, vinculando liberdade com o exercício de virtudes cívicas. A segunda enuncia que muitas vezes é necessário sermos coagidos pelo poder público a desempenhar determinados deveres, já que nos esquecemos de que eles são indispensáveis para a manutenção de nossa liberdade. Ela também é considerada paradoxal, porque vincula liberdade com constrangimento legal, associando liberdade às leis civis.

Skinner reconhece que essas proposições têm sido avaliadas como paradoxais do ponto de vista do pensamento liberal, que assume que a liberdade é um conceito essencialmente negativo, ou seja, que ser livre significa não sofrer interferências ou constrangimentos por parte de outros agentes em nossas escolhas e ações. Por isso, qualquer intervenção por parte do poder público significa uma restrição à liberdade individual.

De fato, a liberdade tem sido geralmente concebida pelos liberais como ausência de impedimento ou de coerção por parte de terceiros nas escolhas e nas ações individuais. Nesta perspectiva, a presença da liberdade manifesta-se pela ausência de oposição de um agente que impeça outro de eleger ou de efetivar seus fins, e 
a sua perda, pela intervenção deliberada de um agente na escolha ou na esfera de ação de outro agente. Desse modo, o debate sobre a liberdade deveria ficar restringido apenas à relação entre agentes, constrangimentos e fins (MacCallum, 1972, pp. 174-193; Benn, 1971, pp. 194-211; Gray, 1980, pp. 507-526).

Do ponto de vista liberal, qualquer limitação à liberdade individual, a fim de que a ordem social possa ser estabelecida e preservada, não deve ser maior do que o necessário para a compatibilização da liberdade de todos, já que quanto mais ampla for a área de não interferência, mais ampla será a liberdade dos indivíduos. Por isso, se é necessário restringir a liberdade no interesse da própria liberdade, protegendo-a de seus excessos, ela só pode ser limitada com este objetivo, sem que seja sacrificada em nome de outros valores, como igualdade ou justiça social (Parent, 1974, pp. 149-167; Day, 1983, pp.17-29; Flew, 1983, pp. 45-59).

Numa série de trabalhos dedicados ao pensamento político de Hobbes, Skinner examina a definição de liberdade como ausência de interferência externa ao movimento de um corpo, impedindo ou restringindo a sua capacidade de movimentar-se, e as definições subsequentes de homem livre como aquele que não é impedido de fazer o que tem capacidade de fazer, quando não encontrar obstáculos externos a sua ação, e de liberdade do súdito como a realização de ações não proibidas pelas leis civis, ou seja, de ações permitidas pelo soberano em razão de seu silêncio, enunciadas principalmente no Leviathan de 1651 (Hobbes, 1985, pp. 261- 274). A sua conclusão é que na reflexão hobbesiana sobre a liberdade estaria a origem desta concepção negativa (Skinner, 1989, pp. 121-151; Id., 1999, pp. 1-29; Id., 2006, pp. 155-184; Id., 2008).

Em A Third Concept of Liberty, Skinner reconhece a influência do ensaio de Isaiah Berlin, Two Concepts of Liberty (1958), no fortalecimento da dicotomia entre liberdade negativa e liberdade positiva. O ensaio de Berlin teria também consagrado a crença de que a concepção negativa seria a única forma inteligível e desejada de tratar a liberdade, já que a concepção positiva, caracterizada 
pela capacidade do indivíduo de orientar seu próprio querer e de agir de acordo com sua vontade, traria sérios prejuízos aos direitos e liberdades dos indivíduos (Skinner, 2002, pp. 237-268). Como a concepção positiva postula que ser livre consiste em ter controle sobre si mesmo (autodomínio) a fim de realizar plenamente a finalidade (autodeterminação) de sua existência (auto perfeição), quando transportada do âmbito individual para o campo social, ela estimularia o controle coletivo sobre as escolhas e ações dos indivíduos, colocando em risco a liberdade individual. O seu caráter nefasto viria de seu pressuposto de que há apenas uma forma de viver e uma única escolha possível, estabelecida por uma lei claramente racional a qual todos devem se submeter (Berlin, 1969).

Em The republican ideal of political liberty, assim como em artigos anteriores, Skinner admite que numa concepção positiva de liberdade as duas proposições enunciadas deixam de ser paradoxais. Isso porque a concepção positiva pressupõe que a natureza humana tem uma essência política; e que somos livres se e somente se somos bem-sucedidos em efetivar esta essência, já que há certos fins específicos que precisamos realizar, mesmo que pela coerção legal, para que sejamos realmente livres (Skinner, 1990, pp. 293-309).

Esta concepção positiva de liberdade parte de duas premissas que podem ser observadas em vários sistemas éticos da antiguidade greco-romana: (1) o ser humano é um ser moral comprometido com certos propósitos característicos de sua natureza; (2) o ser humano é por natureza um animal político. Desse modo, o propósito moral do ser humano é participar de maneira ativa da vida política da comunidade da qual pertence. Nesta perspectiva, só pode ser considerado plenamente livre quem estiver efetivamente engajado em atividades que conduzem ao pleno desenvolvimento de seu ser.

As mesmas premissas encontram-se ainda hoje em alguns autores, como os ditos comunitaristas, que defendem que a li- 
berdade não pode ser apenas um conceito de oportunidade - o agente é livre se tiver a oportunidade para agir - mas deve ser principalmente um conceito de exercício - o agente é livre se realizar o que é necessário realizar, de acordo com sua natureza, que é essencialmente moral e racional (Taylor, 1979, pp. 175-193; MacIntyre, 2001, pp. 249-278).

Apesar de sua possibilidade teórica, Skinner reconhece a dificuldade de efetivação da concepção positiva de liberdade na contemporaneidade. A principal razão apontada para sua inadequação é que ela se fundamenta num monismo ontológico, na realização de um único bem supremo e natural ao ser humano, que não tem mais lugar num mundo que preza e valoriza cada vez mais o pluralismo tanto na escolhas dos fins quanto nas formas de realização dos fins desejados.

Ora, se a concepção positiva deve ser descartada, Skinner pergunta se não haveria uma concepção negativa de liberdade, mais apropriada à defesa dos direitos e liberdades individuais, que acolhesse aquelas proposições - a liberdade necessita da participação ativa dos cidadãos nos negócios públicos; a liberdade depende do constrangimento legal para que os cidadãos cumpram com seus deveres cívicos - sem gerar contradições.

Em sua avaliação, tem sido ignorada uma tradição de pensar a liberdade política, na qual se encontra uma concepção negativa, no sentido da ausência de interferências na esfera da escolha e da ação dos indivíduos, com a inclusão da participação nos assuntos públicos e da coerção legal. Ele propõe então recuperar essa concepção de liberdade, cuja articulação mais incisiva e influente estaria nos escritos republicanos de Maquiavel, em particular nos Discursos sobre a primeira década de Tito-Lívio (1519).

\section{II}

Em trabalhos dedicados à ideia de liberdade em Maquiavel, Skinner procura mostrar que ela acolhe tanto a ausência de impedimentos na escolha e na busca dos fins desejados quanto a 
necessidade da participação política e do constrangimento legal. No pensamento político de Maquiavel, a liberdade de escolher e de fazer o que se deseja, sem sofrer interferências, teria como pressuposto o exercício de determinadas virtudes cívicas e a coerção das leis civis (Skinner, 1983, pp. 3-15; Id., 1984, pp. 193-2211).

Ao contrário de intérpretes que denunciam a falta de uma definição precisa de liberdade, Skinner julga que ela é claramente enunciada por Maquiavel como ausência de interferências desnecessárias na escolha e na busca dos fins desejados. Na sua avaliação, desde o primeiro capítulo de Discursos sobre a primeira década de Tito-Livio é explicitado o que significa ser livre, com a contraposição, baseada na noção romana de libertas, entre homens livres (liber) e escravos (servus), ou seja, entre aqueles que podem agir de acordo com a própria vontade e aqueles que dependem da vontade de terceiros para agir. Como a escravidão é caracterizada pelo constrangimento provocado pela interferência de uma vontade arbitrária, fica evidente que a liberdade é definida pela ausência desta forma de interferência arbitrária, ou seja, pela ausência de dominação.

Skinner sustenta que esta definição torna-se ainda mais explícita na observação, feita nos capítulos seguintes, de que em todo corpo político há dois tipos de cidadãos com disposições contrárias e razões distintas para estimar a liberdade: de um lado, estão os grandes, que desejam adquirir poder para dominar, de outro os cidadãos comuns, o povo, que deseja apenas não ser dominado e viver em segurança. Mas tanto os grandes quanto o povo querem ser livres, no sentido de não encontrar obstáculos na realização de seus propósitos: os grandes querem viver sem embaraços na efetivação de seu comando e o povo quer viver sem perturbações na busca de seu bem estar. Enfim, todos querem ser livres, no

1 Ambos ensaios foram revisados e publicados em Visions of Politics, Vol. 2: Renaissance Virtues. Cambridge: Cambridge University Press, 2002, pp. 160-185 e pp. 186-212. 
sentido de não sofrer interferências arbitrárias e desnecessárias no modo de vida que escolheram para $\mathrm{si}^{2}$.

Em sua interpretação, a liberdade do corpo político e a liberdade de seus membros são tratadas por Maquiavel como interdependentes: o corpo político precisa manter sua liberdade, para que os seus membros desfrutem dos benefícios de uma vida livre, pois quando um corpo político perde sua independência e sua autonomia, tornando-se submisso à vontade de um poder externo ou aos caprichos de um tirano, seus membros deixam de ter uma vida livre. A submissão externa, imposta por uma potência estrangeira, ou interna, imposta por um governo tirânico, resultam claramente na perda da liberdade, já que os membros do corpo político são constrangidos a realizar os fins escolhidos pelos seus dominadores. Assim, para serem livres, os cidadãos devem assegurar a liberdade tanto interna quanto externa de sua cidade³.

A razão pela qual Maquiavel insiste que a preservação da liberdade pessoal depende da manutenção de um Estado livre estaria, segundo Skinner, nos efeitos da ambição, que se manifesta basicamente de duas maneiras. A primeira, no interior do corpo político, com o apetite dos grandes, que querem dominar para realizar seus propósitos`. A segunda, com a cobiça de Estados expansionistas, que desejam expandir seus domínios e conquistar seus vizinhos. A consequência de ambas é a perda da liberdade, já que o povo submetido aos grandes ou conquistado por uma potência estrangeira se vê forçado a agir de acordo com a vontade de seu senhor, ficando reduzido à condição de servidão5.

Para Maquiavel, na interpretação de Skinner, a ameaça externa pode ser combatida pelo estabelecimento de um exército composto por cidadãos. Além de prevenir os costumes ociosos e

2 Skinner cita, em particular, os capítulos 16 e 46 do livro I.

3 Skinner refere-se explicitamente ao capítulo 2 do livro I.

4 A principal referência de Skinner é o capítulo 5 do livro I.

5 As referências citadas são o capítulo 19 do livro II e o capítulo 12 do livro III. 
afeminados, este exército próprio evita as ineficientes e perigosas armas mercenárias e auxiliares ${ }^{6}$. Na defesa da cidade, os cidadãos desenvolvem virtudes, como a coragem no combate aos inimigos da pátria, que são fundamentais para a manutenção da liberdade? .

Já a ameaça interna pode ser combatida pelo cultivo e exercício de determinadas virtudes cívicas, como a sabedoria política, no sentido da habilidade prática de julgar o curso das ações e não temer tomar tais ações; e a moderação, no sentido da disposição de evitar todas as formas de desordem, assegurando que os debates e negócios públicos sejam marcados pela temperança ${ }^{8}$.

Mas a forma mais eficaz de manter a liberdade interna é por meio de boas leis e boas ordenações constitucionais. Por expressar a vontade de todos e não somente o desejo de seus membros mais ambiciosos, as leis civis podem assegurar a liberdade dos cidadãos, protegendo a todos de qualquer interferência arbitrária de poderes discricionários. Além de servir como freio ao caráter ambicioso dos grandes, elas combatem a tendência natural do ser humano à ociosidade e à busca do próprio benefício. Já as boas ordenações constitucionais são capazes de impedir que os grandes ou o povo imponham ao corpo político suas escolhas específicas de vida?.

Skinner sustenta que se Maquiavel chega a reconhecer a importância da educação, do exemplo dos grandes líderes e da religião no combate ao comportamento corruptível dos homens, ele deposita sua maior confiança no poder coercitivo das leis civis. Isso porque só elas são capazes de controlar os apetites desmedidos dos homens, ao instaurar um estado de necessidade artificial, levando-os a agir na realização do bem comum. Por meio do constrangimento legal, os cidadãos podem alcançar a liberdade que tanto desejam, evitando situações de dominação e servidão ${ }^{10}$.

6 As referências citadas são os capítulos 21 e 43 do livro I e os capítulos 10 e 30 do livro II.

7 As referências citadas são os capítulos 25,36 e 37 do livro III.

8 As referências citadas são o capítulo 49 do livro I e o capítulo 35 do livro III.

9 As referências citadas são os capítulos 3, 6, 18, 49 e 55 do livro I.

10 As referências citadas são os capítulos 29, 42 e 58 do livro I. 
Segundo Skinner, há certo ceticismo, por parte de Maquiavel, acerca da capacidade da monarquia em promover a liberdade, que considera a república o regime político mais adequado para efetivá-la e garanti-la. Por isso, aconselha aos cidadãos que, se eles querem evitar situações de dependência interna e de dominação externa, que é o verdadeiro bem comum, devem organizar o corpo político de modo que ele seja governado pela lei ${ }^{11}$; do mesmo modo, se eles desejam a segurança para perseguir os fins desejados, sem sofrer restrições provenientes de situações de dependência ou de submissão, devem instituir e manter um regime republicano, o mais apto para instaurar e assegurar o império da lei ${ }^{12}$;

Assim, na opinião de Skinner, aquelas duas proposições iniciais deixariam de ser paradoxais, no pensamento republicano de Maquiavel. Em primeiro lugar, não haveria contradição em vincular liberdade com participação cívica. Isso porque no âmbito interno a liberdade só pode ser mantida quando os cidadãos são igualmente capazes de desempenhar uma parte relevante nos negócios públicos, evitando que os mais poderosos possam coagir os demais a servir aos seus propósitos; e, no âmbito externo, quando os cidadãos estão dispostos a defender sua pátria, evitando que ela seja conquistada e escravizada por uma potência estrangeira. Em ambos os casos, isso significa estar pronto para se devotar ao bem público, pois tal é a condição necessária para manter a liberdade, evitando a tirania e a dependência pessoal.

Em segundo lugar, não haveria contradição em vincular liberdade com coerção legal, pois os deveres cívicos necessários para assegurar a liberdade nem sempre são praticados de maneira espontânea. Devem então ser suscitados pelas leis civis, capazes tanto de inibir a tendência natural do ser humano para a ociosida-

11 As referências citadas são os capítulos 8 e 41 do livro III. 12 A principal referência de Skinner é o capítulo 2 do livro II. 
de e para a busca do próprio benefício quanto de promover ações em vista do bem comum.

$\mathrm{Na}$ avaliação de Skinner, Maquiavel vincula liberdade com virtude cívica e coerção legal sem fazer apelo a uma concepção positiva de liberdade, ou seja, sem argumentar que somos seres morais com certos propósitos e que só estamos de posse da liberdade quando esses propósitos são plenamente realizados. A participação ativa dos cidadãos nos assuntos públicos não é considerada um bem em si mesmo, um fim adequado ao ser humano, objetivamente inscrito em sua natureza, mas simplesmente um meio eficiente para que os cidadãos possam efetivar suas escolhas e perseguir os fins desejados. Como seria irracional querer o fim e recusar os meios que o garantem, os cidadãos devem reconhecer que a prática de virtudes cívicas é condição necessária para a liberdade. Do mesmo modo, eles devem reconhecer que as leis civis são instrumentos imprescindíveis para a liberdade, já que elas garantem o cumprimento dos deveres cívicos e a ausência de dominação nas relações sociais.

III

Apesar de contundente, a interpretação de Skinner tem alguns aspectos no mínimo problemáticos. O primeiro é a afirmação de que há uma clara e precisa definição de liberdade em Maquiavel. Ora, vários estudos já demonstraram que o termo libertà aparece nos escritos políticos de Maquiavel com uma pluralidade de sentidos (Colish, 1971, pp. 323-350): é utilizado para indicar a livre escolha do ser humano (Maquiavel, 2007, I, 3), para caracterizar a independência das cidades que não estão submetidas a potências estrangeiras (Ibid., I, 2; II, 2; II, 19), para diferenciar governos que permitem um vivere politico ou vivere civile de governos tirânicos (Ibid., I, 16; III, 7; III, 8), entre tantas outras acepções.

O segundo aspecto problemático é que Skinner parece tratar a liberdade do corpo político como análoga à liberdade de seus membros, e não como meramente interdependentes. Isso explica- 
ria o fato de ele citar passagens que se referem claramente à liberdade das cidades para corroborar afirmações a respeito da liberdade dos cidadãos (Ibid., III, 8; III, 41). De fato, em sua análise, ele não diferencia a liberdade externa - independência em relação a uma potência estrangeira - da liberdade interna - não estar sujeito a um governo tirânico -, ou ambas da liberdade pessoal - não estar submetido a uma vontade arbitrária.

Ora, ao tratar da liberdade no âmbito externo, Maquiavel parece simplesmente manter a teoria medieval das corporações, segundo a qual uma comunidade era considerada livre se possuísse prerrogativas e isenções que sinalizassem sua independência em relação a outros poderes constituídos. No caso das cidades livres, a principal prerrogativa era a autonomia de estabelecer as próprias leis sem se submeter à jurisdição de potências estrangeiras. Ao descrever uma cidade livre como príncipe de si mesma (principe di se stessa), Maquiavel utiliza uma fórmula muito próxima da encontrada em Barlolus e em outros juristas medievais para definir as cidades independentes de iure do império (civitas sibi princeps).

Mas uma cidade independente nem sempre garante aos seus cidadãos um modo de vida livre. Ela pode não estar submetida ao domínio de uma potência estrangeira, sendo autônoma, e estar sujeita a um tirano, que lhe garante a independência externa, mas lhe impõe o julgo interno. Assim, se a liberdade externa é uma condição necessária, ela não é suficiente, pois não garante a liberdade interna ou a liberdade pessoal'³.

Ao tratar da liberdade no âmbito interno, Maquiavel parece associá-la às instituições e a certas formas constitucionais capazes

13 Na descrição da revolta da plebe contra os patrícios, por exemplo, Tito Lívio enfatiza: "os plebeus consumiam-se no ódio aos patrícios, sobretudo por causa da escravidão por dívidas. Indignados, diziam que eram aprisionados e oprimidos em sua própria pátria e por seus próprios concidadãos, embora combatessem no exterior pela liberdade da república. A plebe era mais protegida na guerra do que na paz, mais livre entre os inimigos do que entre seus próprios concidadãos". Tito Lívio, História de Roma, L. II, 23 , p. 136 . 
de estabelecer boas leis e boas ordenações (Maquiavel, 2007, I, 2; I, 4; I, 16; I, 18; I, 4O; I, 49; II, 2; II, 4; III, 3; III, 12). Quase sempre ela é identificada com o regime republicano, em oposição à tirania, à licença e à facção, para marcar a diferença entre regimes políticos que permitem um modo de vida livre (vivere politico ou vivere civile) e os que impõem a servidão (Ibid., I, 16; I, 29; I, 35; II, 2; III, 8). Porém, às vezes, ela aparece associada ao governo de uma só pessoa, desde que o príncipe não seja absoluto ou tirânico. O importante para a liberdade interna é que o regime político estabelecido garanta a segurança interna, a ordem pública e a prosperidade de todos os membros do corpo político, por meio de uma legislação eficiente e boa (Ibid., I, 2; III, 5).

Já ao tratar da liberdade pessoal, a principal referência de Maquiavel parece ser mesmo a noção romana de libertas, tão destacada por Skinner ${ }^{14}$. Na tradição jurídica de Roma, libertas atribuía ao cidadão um status legal e moral, que lhe garantia direitos e proteções negados aos que não detinham a cidadania. $\mathrm{O}$ termo libertas identificava a ausência de sujeição ao domínio de outra pessoa (dominium), ou seja, indicava que a pessoa não estava sob o poder (in potestas) nem sob a jurisdição de outrem (alieni iuris), como os servos ou escravos. A liberdade pessoal implicava assim na capacidade legal de desfrutar certos direitos (persona sui iuris) e na ausência de submissão a vontade de outrem (Wirszubski, 1968, pp. 1-30; Brunt, 1988, pp. 281-350).

Porém, ao não diferenciar a liberdade externa da liberdade interna do corpo político e ambas da liberdade pessoal, Skinner induz o leitor a acreditar que a ideia de liberdade em Maquiavel está centrada apenas nessa noção romana de libertas, acentuando em demasia o seu caráter legal. Não se pode deixar de atentar para o fato de que libertas aparecia no direito romano quase sem-

14 Nos últimos trabalhos, Skinner passou a denominar a concepção maquiaveliana de noção neo-romana de liberdade. 
pre associada a civitas, indicando que a liberdade pessoal estava condicionada à cidadania. Somente um cidadão desfrutava de direitos, pessoais e políticos, que constituíam sua liberdade. Em Roma, a liberdade não era concebida em termos da autonomia da vontade, como uma faculdade do indivíduo garantida pela lei civil, mas em termos das relações políticas estabelecidas no interior da cidade.

Ao enfatizar fortemente o aspecto legal da concepção maquiaveliana de liberdade, a interpretação de Skinner faz da virtude cívica apenas um meio capaz de garantir a liberdade. Não se trata evidentemente de defender a presença de uma noção de liberdade positiva nos escritos políticos de Maquiavel, como parecem sugerir as interpretações de Hans Baron (Baron, 1966) ou John Pocock (Pocock, 1975). É muito difícil associar a concepção maquiaveliana de liberdade à defesa de uma virtude cívica atuante, inspirada no pressuposto aristotélico de que os seres humanos só realizam sua natureza quando participam efetivamente dos negócios públicos. Mas, entre o caráter meramente instrumental e o valor intrínseco da virtude cívica, há outras possibilidades de conceber a sua relação com a liberdade.

Outro problema em sua interpretação é que o contraste enfatizado entre homens livres e homens escravos, tão decisivo na sua argumentação, é utilizado por Maquiavel para tratar da fundação de cidades edificadas por forasteiros. Os mencionados homens livres, que se opõem aos que dependem de outrem, são os fundadores dessas cidades, homens excepcionais, exemplificados pelas figuras de Moisés e Enéas (Maquiavel, 2007, I, 1). A intenção de Maquiavel parece ser simplesmente vincular a fundação do corpo político com a liberdade, como se a criação de um novo ente político fosse um momento privilegiado de manifestação da liberdade.

Mas o principal problema da interpretação de Skinner está na suposição de que grandes e povo querem viver igualmente de maneira tão livre quanto for possível, sem sofrer interferências desnecessárias no modo de vida que escolheram para si. Se Skin- 
ner reconhece que Maquiavel expõe as disposições contrárias dos cidadãos para estimar a liberdade - dos grandes, dominar, do povo, não ser dominado - e as suas diferentes razões - dos grandes, exercer o poder, do povo, viver em segurança -, ele não leva em conta as consequências dessa oposição, ao supor que todos os membros do corpo político têm o mesmo objetivo: estar livre de obstáculos que impeçam a realização dos fins desejados. Por isso eles estabelecem as leis civis, como o meio mais eficaz de assegurar sua liberdade.

Ora, uma das principais características do pensamento político de Maquiavel é a constatação da existência em todo corpo político de humores distintos dos quais nascem apetites opostos: o desejo dos grandes de dominar e oprimir; o desejo do povo de não ser dominado nem oprimido. Esses desejos são claramente antagônicos e visam objetivos conflitantes. Se eles podem se afirmar concomitantemente, não podem ser saciados totalmente, uma vez que a plena realização de um implica na impossibilidade de satisfação do outro. Em razão da oposição desses desejos, da diversidade de seus objetos e da impossibilidade de transpor a dessemelhança entre eles, instaura-se um inevitável conflito no interior do corpo político (Lefort, 1972).

Não parece então ser possível, como faz Skinner, pensar numa conjunção de objetivos entre os grandes e o povo. Os seus diferentes humores não expressam apenas interesses distintos, que poderiam ser ajustados por um cálculo racional ou regulados pela ação de uma suposta mão invisível; manifestam-se intensamente em apetites irredutíveis, que não podem ser harmonizados, por exemplo, pelas cláusulas de um contrato. Afinal, desejos não se negociam. Eles podem ser reprimidos ou saciados, parcial ou totalmente, mas jamais conciliados. Parece ser um equívoco acreditar na possibilidade de um acordo entre desejos que se definem a si mesmos na confrontação. Aliás, quando os grandes e o povo passam a ter o mesmo desejo - como aconteceu em Roma no tempo da promulgação da lei agrária pelos irmãos Graco, quando 
ambos ambicionavam riquezas e honras -, a liberdade está condenada (Maquiavel, 2007, I, 37).

A desunião entre os grandes e o povo é apresentada por Maquiavel como intrínseca e inerente a todo corpo político, provocando embates que não podem ser solucionados em definitivo por uma determinada estrutura constitucional ou por uma ordenação específica, mas apenas mediados temporariamente, pelas instituições políticas. Tais instituições seriam as únicas capazes de manter os diferentes humores em equilíbrio, saciando em parte os apetites deles decorrentes, para que um não se sobreponha totalmente ao outro, evitando o desequilíbrio que causa a doença e, consequente, a morte do corpo político.

É por isso que Maquiavel insiste tanto na necessidade de criar mecanismos institucionais que permitam a contínua expressão dos diferentes humores. Em sua avaliação, é imprescindível a existência de meios e espaços públicos nos quais os conflitos provocados pelos diversos apetites possam se expressar, para que não seja preciso recorrer à força e nem se suprima a possibilidade de convivência entre as partes constitutivas do corpo político. Sem tais mecanismos, os humores são reprimidos, gerando facções e partidarismo, que colocam em risco a existência do próprio corpo político.

Assim, Skinner deveria ter dado mais atenção à análise de Maquiavel sobre as dissensões entre patrícios e plebeus, que ocupa um lugar central em sua reflexão sobre a origem e a manutenção da liberdade em Roma. Tratadas por uma série de termos, como inimizades, discórdias civis, divisões, disputas, que causaram desordens e tumultos na jovem república, essas dissensões são consideradas as principais responsáveis pelo surgimento de leis em favor da liberdade. Não por acaso, os Discursos concentram-se nos dez primeiros livros da História de Roma de Tito Lívio, que narram justamente essas dissensões e suas consequências ${ }^{15}$. 
Enquanto o republicanismo clássico defendia a necessidade da instauração da concórdia e da unidade para desfrutar da vida civil, Maquiavel sustenta que é preciso aprender a preservá-la no interior dos conflitos. O melhor exemplo vinha da República de Roma, onde haviam sido criados mecanismos institucionais capazes de dar vazão aos desejos opostos de patrícios e de plebeus, para que as suas diferenças pudessem se expressar. Assim, as dissensões na Roma Republicana tiveram efeitos positivos - geraram boas leis e consequentemente a manutenção da liberdade - porque ocorreram na esfera pública e foram mediadas por mecanismos institucionais.

Também chama a atenção o silêncio de Skinner sobre a opção de Maquiavel em atribuir a guarda da liberdade ao povo $^{16}$. Sem entrar no debate do que seria esta guarda da liberdade, a razão de sua escolha é claramente explicitada: o desejo do povo de não ser dominado parece estar mais próximo da liberdade, já que revela uma face importante de sua manifestação, que é a ausência da ambição pelo poder. Por isso, o povo tem uma propensão menor de violar a liberdade. O seu desejo em viver sem ser dominado dificilmente se opõe à existência de um governo livre, no qual a liberdade dos cidadãos tem mais possibilidade de se efetivar.

Além disso, se a ambição dos grandes pode realmente ser associada à concepção negativa de liberdade - eles desejam não sofrer constrangimentos ou interferências a fim de dominar e comandar -, o mesmo não pode ser dito a respeito do desejo do povo. Para não ser dominado, o povo necessita mais do que a simples ausência de interferência em suas escolhas e ações. O povo precisa ter uma ação política permanente em oposição ao apetite dos grandes. Por isso, a participação ativa dos cidadãos não

parte da plebe, a 287 A.C., a promulgação da Lei Hortênsia, que garantia aos decretos da plebe o mesmo status daqueles do senado.

16 McCormick critica Skinner e outros neo-republicanos por negligenciar este aspecto fundamental do conceito de liberdade em Maquiavel (McCormick, 2003, pp. 615643). 
pode ser considerada meramente instrumental. O povo precisa forçar constantemente a ordem constitucional estabelecida, a fim de que ela possa acolher suas demandas por garantias contra a dominação. A liberdade só pode ser conquistada por este combate contínuo contra a ambição daqueles que querem dominar o corpo político ${ }^{17}$.

Enfim, Skinner não concede a devida importância a aspectos relevantes do pensamento político de Maquiavel, que são determinantes para sua concepção de liberdade. Ao negligenciá-los, a concepção maquiaveliana que surge de sua interpretação aparece como uma modalidade da liberdade negativa, na qual as leis civis têm um papel de reguladoras dos espaços de não interferência e de protetoras contra qualquer intervenção desnecessária; e na qual as virtudes cívicas devem ser cultivadas e praticadas como um meio, para que os cidadãos tenham assegurada a ausência de impedimentos na escolha e na busca dos fins desejados.

Skinner perde assim a oportunidade, ao revisitar o republicanismo de Maquiavel, em particular sua concepção de liberdade, e de resgatar a sua principal contribuição ao republicanismo moderno, que é a ideia de que é preciso instaurar e manter a liberdade, apesar dos conflitos inerentes a todo corpo político.

Referências bibliográficas

BARON, H. The crisis of the early Italian Renaissance. Princeton: Princeton University Press, 1966.

BENN, S. I. "Being Free to Act, and Being a Free Man", Mind, n. 8o, 1971, pp. 194-211.

BERLIN, I. "Two Concepts of Liberty". In: Four Essays on Liberty. Oxford: Oxford University Press, 1969, pp. 118-172.

17 Por exemplo, ao tratar do resultado da lei agrária, Maquiavel afirma "é tão grande a ambição dos grandes que, se não sofrer oposição por várias vias e de vários modos numa cidade, logo a levará à ruína. De modo que, embora o conflito da lei agrária tenha demorado trezentos anos para acarretar a servidão de Roma, isso teria ocorrido muito mais cedo caso a plebe não tivesse refreado a ambição dos nobres". (Maquiavel, 2007, I, 37). 
BRUNT, P. A. "Libertas in the Republic". In: The Fall of the Roman Republica. Oxford: Clarendon Press, 1988, pp. 281-350.

COLISH, M. "The Idea of liberty in Machiavelli”, Journal of the History of Ideas, v. 32, n. 3, 1971, Pp. 323-350.

DAY, J. P. “Individual Liberty”. In: GRIFFITHS, A. P. (ed.). Of Liberty. Cambridge: Cambridge University Press, 1983, pp. 17-29.

FLEW, A. "Freedom Is Slavery: a slogan for our new philosopher kings”. In: GRIFFITHS, A. P. (ed.). Of Liberty. Cambridge: Cambridge University Press, 1983, pp. 45-59.

GRAY, J. N. "On negative and positive liberty", Political Studies, n. 28,1980 , pp. 507-526.

HOBBES, T. Leviathan. London: Penguin Books, 1985.

LEFORT, C. Le travail de l'ouvre Machiavel. Paris: Gallimard, 1972.

MACCALLUM, G. C. "Negative and Positive Freedom". In: LASLETT, P.; SKINNER, Q. (ed.). Philosophy, Politics and Society. Oxford: Basil Blackwellfa, 1972, pp. 174-193.

MACINTYRE, A. Depois da Virtude. Bauru: Edusc, 2001.

MAQUIAVEL, N. Discursos sobre a primeira década de Tito Lívio. São Paulo: Martins Fontes, 2007.

MCCORMICK, J. P. "Machiavelli against republicanism on Cambridge School's Guicciardinan Moments", Political Theory, n. 31, 2003, pp. 615-643.

PARENT, W. "Some recent work on the concept of liberty", American Philosophical Quarterly, n. 11, 1974, pp. 149-67.

POCOCK, J. The Machiavellian moment: Florentine political thought and the Atlantic Republican tradition. Princeton: Princeton University Press, 1975.

SKINNER, Q. "Machiavelli on the Maintenance of Liberty", Politcs, v. 18, n. 2, 1983, pp. 3-15. . "The idea of negative liberty: philosophical and historical perspectives". In: RORTY, R.; SCHNEEWIND, J.; SKINNER, Q. (ed.). Philosophy in History. Cambridge: Cambridge University Press, 1984, pp. 193-221. 
. "The Paradoxes of Political Liberty". In: The Tanner Lectures on Human Values. Harvard University, 1984, pp. 227250.

. "Thomas Hobbes on the proper signification of liberty". In: Transactions of the Royal Historical Society, 1989, pp. 121-151.

. "The republican ideal of political liberty". In: BOCK, G.; SKINNER, Q.; VIROLI, M. (ed.). Machiavelli and Republicanism. Cambridge: Cambridge University Press, 1990, pp. 293-309.

. As Fundações do Pensamento Político Moderno. São Paulo: Companhia das Letras, 1996.

. "Hobbes and the Purely Artificial Person of the State", The Journal of Political Philosophy, v. 7, n. 1, 1999, pp. 1-29. . "A Third Concept of Liberty", Proceedings of the British Academy, n. 117, 2002, pp. 237-268.

. "Hobbes on Representations", European Journal of Philosophy, 2006, v. 13, n. 2, pp. 155-184.

. Hobbes and Republican Liberty. Cambridge: Cambridge University Press, 2008.

TAYLOR, C. "What's Wrong with Negative Liberty". In: ALAN, R. (ed.). The Idea of Freedom.. Oxford: Oxford University Press, 1979, pp. 175-193.

TITO LÍVIO. História de Roma. São Paulo: Ed. Paumape, 1989. WIRSZUBSKI, C. Libertas as a Political Idea at Rome during the Late Republic and Early Principate. Cambridge: Cambridge University Press, 1968. 